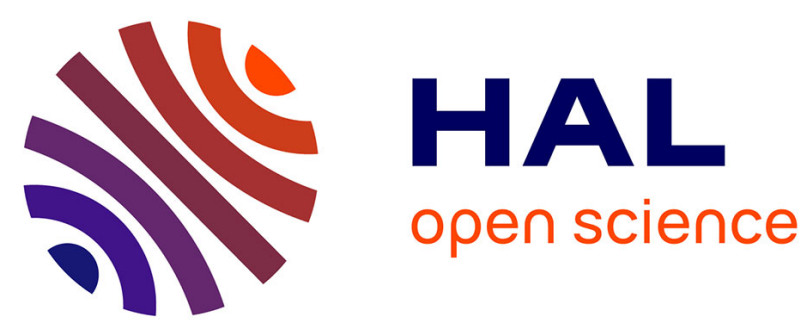

\title{
Processing-induced-transformations (PITs) during direct compression: Impact of tablet composition and compression load on phase transition of caffeine
}

Audrey Juban, Stéphanie Briançon, François Puel

\section{- To cite this version:}

Audrey Juban, Stéphanie Briançon, François Puel. Processing-induced-transformations (PITs) during direct compression: Impact of tablet composition and compression load on phase transition of caffeine. International Journal of Pharmaceutics, 2016, 501 (1-2), pp.253-264. 10.1016/j.ijpharm.2016.01.079 . hal-01279575

\section{HAL Id: hal-01279575}

https://hal-centralesupelec.archives-ouvertes.fr/hal-01279575

Submitted on 13 Apr 2017

HAL is a multi-disciplinary open access archive for the deposit and dissemination of scientific research documents, whether they are published or not. The documents may come from teaching and research institutions in France or abroad, or from public or private research centers.
L'archive ouverte pluridisciplinaire HAL, est destinée au dépôt et à la diffusion de documents scientifiques de niveau recherche, publiés ou non, émanant des établissements d'enseignement et de recherche français ou étrangers, des laboratoires publics ou privés. 
To cite this article: A. JUBAN, S. BRIANCON, F. PUEL, 2016 Process-induced-transformations (PITs) during direct compression: Impact of tablet composition and compression load on phase transition of caffeine. International Journal of Pharmaceutics 501, 253-264

http://dx.doi.org/10.1016/j.ijpharm.2016.01.079

\title{
Title : Processing-induced-transformations (PITs) during direct compression: Impact of tablet composition and compression load on phase transition of caffeine.
}

\author{
Author names and affiliations: \\ Audrey JUBANa ${ }^{a}$, Stéphanie BRIANCONa ${ }^{a}$ François PUEL ${ }^{a, b}$. \\ a Université de Lyon, F-69622 Lyon, France. Université Lyon 1, Villeurbanne, CNRS, UMR5007, \\ Laboratoire d'Automatique et de Génie des Procédés (LAGEP), CPE-Lyon, 43 bd du 11 Novembre 1918, \\ 69622 Villeurbanne Cedex, France \\ ${ }^{b}$ Université Paris Saclay, CentraleSupélec Paris, Laboratoire de Génie des Procédés et Matériaux \\ (LGPM), EA 4038, Grande Voie des Vignes, 92290 Châtenay-Malabry, France
}

Corresponding author: Prof. F. Puel, +33 (0)1 411311 09, francois.puel@centralesupelec.fr

\begin{abstract}
In the pharmaceutical field, solid-state transitions that may occur during manufacturing of pharmaceuticals are of great importance. The phase transition of a model API, caffeine form I (CFI), was studied during direct compression process by analysing the impacts of the operating conditions (process and formulation). This work is focused on two formulation parameters: nature of the diluent and impact of the caffeine dilution, and one process parameter: the compression pressure that may impact the phase transition of CFI. Tablets were made from pure CFI and from binary mixture of $\mathrm{CFI} /$ diluent (microcrystalline cellulose or anhydrous dicalcium phosphate). A kinetic study performed during six months helped to highlight the influence of these parameters on the CFI transition degree. Results showed a triggering effect of the direct compression process, transformation was higher in tablets than in uncompressed powders. Whatever the pressure applied, CFI transition degree was almost constant and uniformly occurring throughout the tablet volume. Nevertheless, several differences on the evolution of the CFI transition degree were observed between binary mixtures of $\mathrm{CFI} /$ diluent. An analysis of the transition mechanism with a stretched exponential law of the JohnsonMehl-Avrami model shows that tableting accelerates the polymorphic transition without modifying its mechanism controlled by nucleation only.
\end{abstract}




\section{Keywords}

Polymorphic transformation

Processing induced transition (PITs)

Tabletting

Direct compression

DSC

Johnson-Mehl-Avrami model

\section{Chemical compounds studied in this article}

Caffeine (PubChem CID: 2519); Microcrystalline cellulose (PubChem CID: 14055602); Anhydrous dicalcium phosphate (PubChem CID: 24441) 


\section{Introduction}

Solid-state transitions during manufacturing of pharmaceuticals are of great importance for pharmaceutical industry. For several years, processing-induced-transformations (PITs) in pharmaceutical manufacturing have been reported. Many authors (Morris et al., 2001; Brittain, 2002; Zhang et al., 2004; Descamps et al., 2007) have started to set up theoretical and experimental approaches of these transformations. The PITs includes all the physical or chemical transformations of molecular crystals caused by one or more steps of preparation and shaping processes. In the pharmaceutical field, these transformations have both an economic and health impact. These changes can affect the quality of products produced and it is possible that non-compliant consignments are not released on the market for this reason (Bauer et al., 2001). Today, manufacturers have no control over these phenomena. The theoretical approach of the PITs (Morris et al., 2001; Petit and Coquerel, 2004) is recent and proposes kinetics and thermodynamics consideration of these transformations. This theory assumes that each step of a process can generate a stress (thermal, mechanical, or chemical) for the product which cause a shift in the thermodynamic equilibrium of the system. In the literature, the more documented PITs are the ones observed during milling, granulation and compression.

Tablets are the most common dosage form for oral administration in the world (Wu and Seville, 2009). The use of direct compression has rapidly increased (Zhang et al., 2003) in the past few years because of its economic interest and its process which removes the steps of wet granulation and drying processes. The basis of the direct compression is to add a key component (generally a diluent) in the formulation which possesses the necessary degree of fluidity and compressibility. If it necessary, other ingredients could be included, such lubricant, a glidant and/or a disintegrating agent (Armstrong, 2002). However, active pharmaceutical ingredients (APIs) and excipients may exist under different crystalline forms or amorphous phase depending on the nature of the treatment that they received. Many parameters in the process itself could have an impact on the average transformation in final tablets like pressure, temperature and mechanical stress. It is not uncommon to observe phase transition as polymorphic transformation during the compression process (Chan and Doelker, 1985; Lefebvre et al., 1986; Boldyreva et al., 2006; Otsuka et al., 2009; Hubert et al., 2011). The consequences of this phenomenon are an unpredictable solid phase composition and may induce a modification of bioavailability (Doelker, 2002, Ticehurst and Marziano, 2015).

In this study, caffeine $\left(\mathrm{C}_{8} \mathrm{H}_{10} \mathrm{~N}_{4} \mathrm{O}_{2}\right)$ was used as an API model. Caffeine is one of the most widely used psychoactive drug in the world and it is cheap and readily available (Sahoo, 2015). This common molecule is well known for polymorphism studies (Pirttimäki et al., 1993; Lehto and Laine, 1998; Manduva et al., 2008; Mazel et al., 2011) which presents a simple enantiotropic behaviour. 
Two polymorphic forms of caffeine is known, the Form II is the stable polymorph at room temperature until $145^{\circ} \mathrm{C}$ and the Form I is stable at ambient pressure from the transition temperature $\left(145^{\circ} \mathrm{C}\right)$ to its melting point $236^{\circ} \mathrm{C}$ (Pinto and Diogo, 2006). The kinetics of the phase transformation of caffeine form I into form II at solid state was studied at $363 \mathrm{~K}$ using time-resolved dielectric relaxation spectroscopy (Decroix et al., 2008) and law frequency raman spectroscopy (Hedoux et al., 2011b). Hédoux et al. (2013) have thoroughly investigated the transition of the caffeine form I to form II by hydrostatic pressurizing and grinding. They have shown that an intermediate metastable form may exist under pressure or stabilize during the grinding, but disappear as soon as the application of pressure or the milling process is stopped.

The purpose of this study was to improve the understanding of the PITs in a direct compression process. This work is focused on two formulation parameters: nature of the diluent and the impact of the caffeine dilution, and one process parameter: the compression pressure that may impact the phase transition of the caffeine form I. Tablets were made at three different compression pressures. Two diluents exhibiting different behaviours under compression (plastic: microcrystalline cellulose and fragmentary: anhydrous dicalcium phosphate (Ilkka and Paronen, 1993)) and their mixtures with caffeine form I were studied. The determination of the transition degree of caffeine was performed by thermal analysis. 


\section{Materials and methods.}

\subsection{Materials}

The material used in this study is caffeine Form I (CFI). It was obtained by using the same method than Hubert et al. (2011) which based on these suggested by Derollez et al. (2005) and Griesser et al. (1999) as follows. Commercial anhydrous caffeine Form II (CFII), purchased from Cooper, was heated to $170^{\circ} \mathrm{C}$ in an oven for 24 hours in order to anneal the Form II. Freshly Form I was quickly cooled in liquid nitrogen until room temperature. On each batch a Differential Scanning Calorimetry (DSC) analysis was performed at a heating rate of $10^{\circ} \mathrm{C} / \mathrm{min}$ from $20^{\circ} \mathrm{C}$ to $270^{\circ} \mathrm{C}$ and no trace of the transition $\| \rightarrow \mid$ was found (Fig. 1). Microcrystalline cellulose (MCC), Avicel ${ }^{\circledR}$ PH-102, was obtained from FMC Biopolymer and anhydrous dicalcium phosphate (DCPA) from JRS Pharma.

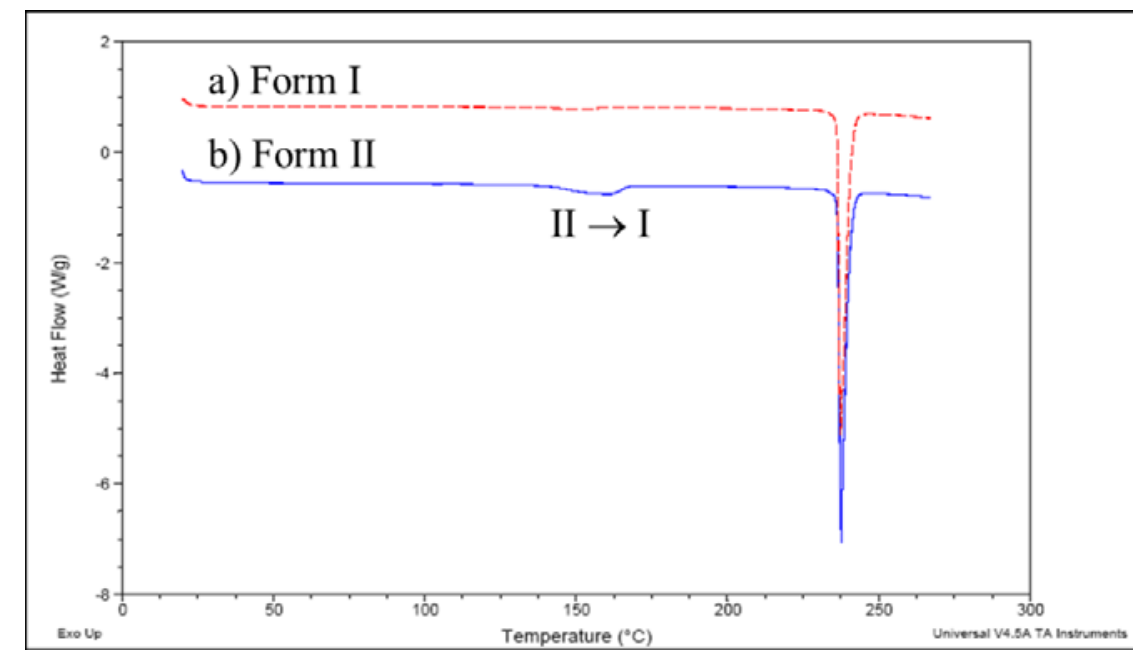

Fig.1. (a) DSC curve of caffeine Form I. (b) DSC curve of caffeine Form II with a Y-axis offset for comparison.

The particle size distribution for these two materials was measured with a Mastersizer 3000 using an AeroS dry dispersion unit (Malvern Instruments, U.K.). Three measurements of the particle size distribution were performed on each powder. The Fraunhofer model was selected in order to transform the dynamic light scattering measurements in a particle size distribution. The resulting volume density function distribution was averaged. The calculation of the different standard percentile ( $D_{v} 10, D_{v} 50$ and $D_{v} 90$ ) is performed following the British standard BS2955.1993. Their Their values with their standard deviations are listed in Table 1. 
${ }^{\text {a }}$ Average calculated from 3 measurements

\begin{tabular}{cccc}
\hline Powders & $\begin{array}{c}\mathbf{D}_{\mathbf{v}} \mathbf{1 0}{ }^{\mathrm{a}} \\
(\mu \mathrm{m})\end{array}$ & $\begin{array}{c}\mathbf{D}_{\mathbf{v}} \mathbf{5 0} \\
(\mu \mathrm{m})\end{array}$ & $\begin{array}{c}\mathbf{D}_{\mathbf{v}} \mathbf{9 0} \mathbf{a}^{\mathrm{a}} \\
(\mu \mathrm{m})\end{array}$ \\
\hline CFI & $19.7 \pm 0.7$ & $67.8 \pm 2.1$ & $160.5 \pm 3.5$ \\
MCC & $28.3 \pm 0.1$ & $119.0 \pm 0.0$ & $268.7 \pm 1.2$ \\
DCPA & $54.8 \pm 5.0$ & $182.7 \pm 11.0$ & $318.7 \pm 14.0$ \\
\hline
\end{tabular}

Table 1: Particle size distribution parameters of CFI, MCC and DCPA ( $n=3)$

\subsection{Tablet preparation}

Cylindrical tablets were prepared with a binary mixture of anhydrous caffeine Form I (a day after its manufacture) and MCC or DCPA as a binder/diluent. Each diluent was mixed in various proportions with caffeine content of $60,78,90 \mathrm{wt} \%$ of CFI for MCC, and 40, 60 and $80 \mathrm{wt} \%$ of CFI for DCPA. The blending was performed with a tridimensional mixer (Turbula ${ }^{\circledR} \mathrm{T} 2 \mathrm{~F}$ ) at a rotational rate of $49 \mathrm{rpm}$ (for 10 minutes). A series of pure CFI tablets (100 wt\%) was also made. All compacts were made at constant mass (about $300 \mathrm{mg}$ ) by using a compaction simulator Styl'One Classic (Medelpharm, Beynost, France) and its data acquisition software (Analis, 2.03 versions, Medelpharm). This tableting press is a single station press. Compression was made by the lower punch. The compression forces were measured with strain gauges located on the upper and lower punch holders with an accuracy of $0.5 \%$ of full scale, and the displacements of the punches were monitored using Linear Variable Differential Transformers (LVDTs) with an accuracy of $20 \mu \mathrm{m}$ for upper punch and $50 \mu \mathrm{m}$ for lower punch. Standard Euro D tools with flat-punches $11.28 \mathrm{~mm}$ of diameter (corresponding to an area of about $1 \mathrm{~cm}^{2}$ ) were fitted on the simulator.

The deformation of the machine (including punch deformation) was taken into consideration and measured before experiments to correct the values of the displacement. In this work, tablets were produced (without lubricant) with one main compression driven by force under three different compression forces $(5 \mathrm{kN}, 10 \mathrm{kN}, 20 \mathrm{kN})$ corresponding at $50 \mathrm{MPa}, 100 \mathrm{MPa}$ and $200 \mathrm{MPa}$ in compression pressure, respectively. The tablet weights and thicknesses (shown in Table 2) were measured just after compression according to the European Pharmacopoeia method section 2.09.05 (European Pharmacopoeia, 2014). The storage was made at room temperature during six months (over one year the temperature may vary in a range of from 18 to $30^{\circ} \mathrm{C}$ ). 


\begin{tabular}{|c|c|c|c|c|c|c|}
\hline \multicolumn{7}{|c|}{$\begin{array}{l}{ }^{\text {a }} \text { Measured by helium pycnometry Hubert (2012) } \\
{ }^{\mathrm{c}} \text { Calculated from true density of pure MCC or pur } \\
\left(\rho_{\text {MCC }}=1.561 \mathrm{~g} \cdot \mathrm{cm}^{-3} \text { and } \rho_{\text {DCPA }}=2.890 \mathrm{~g} \cdot \mathrm{cm}^{-3}\right)\end{array}$} \\
\hline Diluent & Composition & $\begin{array}{c}\text { Compression } \\
\text { load }(P)\end{array}$ & $\begin{array}{c}\text { Tablet } \\
\text { weight }^{\mathrm{b}}(w)\end{array}$ & $\begin{array}{c}\text { Tablet } \\
\text { thickness }^{\mathrm{b}}(\mathrm{t})\end{array}$ & $\begin{array}{l}\text { Particle } \\
\text { density } \\
\left(\rho_{\text {blend }}\right)\end{array}$ & $\begin{array}{c}\text { Tablet } \\
\text { Density }^{\text {b }(d)}\end{array}$ \\
\hline \multirow[t]{4}{*}{$(-)$} & (wt\% CFI) & (MPa) & (mg) & $(\mathrm{mm})$ & $\left(\mathrm{g} \cdot \mathrm{cm}^{-3}\right)$ & $\left(\mathrm{g} \cdot \mathrm{cm}^{-3}\right)$ \\
\hline & & 200 & $301.8 \pm 1.7$ & $2.27 \pm 0.02$ & & $1.333 \pm 0.004$ \\
\hline & 100 & 100 & $298.6 \pm 2.5$ & $2.38 \pm 0.02$ & $1.446^{\mathrm{a}}$ & $1.253 \pm 0.003$ \\
\hline & & 50 & $303.3 \pm 2.3$ & $2.64 \pm 0.02$ & & $1.147 \pm 0.005$ \\
\hline \multirow{9}{*}{ MCC } & & 200 & $302.5 \pm 1.2$ & $2.25 \pm 0.01$ & & $1.343 \pm 0.006$ \\
\hline & 90 & 100 & $301.4 \pm 2.2$ & $2.41 \pm 0.01$ & $1.457^{c}$ & $1.253 \pm 0.004$ \\
\hline & & 50 & $302.4 \pm 2.5$ & $2.63 \pm 0.00$ & & $1.149 \pm 0.003$ \\
\hline & & 200 & $293.2 \pm 4.5$ & $2.18 \pm 0.03$ & & $1.344 \pm 0.003$ \\
\hline & 78 & 100 & $294.0 \pm 4.5$ & $2.40 \pm 0.03$ & $1.470^{c}$ & $1.227 \pm 0.007$ \\
\hline & & 50 & $297.0 \pm 2.9$ & $2.68 \pm 0.02$ & & $1.108 \pm 0.003$ \\
\hline & & 200 & $301.2 \pm 2.3$ & $2.22 \pm 0.02$ & & $1.361 \pm 0.002$ \\
\hline & 60 & 100 & $300.4 \pm 2.3$ & $2.42 \pm 0.02$ & $1.490^{c}$ & $1.240 \pm 0.004$ \\
\hline & & 50 & $302.4 \pm 1.8$ & $2.75 \pm 0.01$ & & $1.099 \pm 0.003$ \\
\hline \multirow{9}{*}{ DCPA } & & 200 & $300.3 \pm 3.0$ & $2.12 \pm 0.02$ & & $1.397 \pm 0.005$ \\
\hline & 80 & 100 & $301.4 \pm 2.0$ & $2.27 \pm 0.02$ & $1.607^{c}$ & $1.311 \pm 0.003$ \\
\hline & & 50 & $298.5 \pm 3.2$ & $2.44 \pm 0.04$ & & $1.212 \pm 0.006$ \\
\hline & & 200 & $301.9 \pm 2.7$ & $2.02 \pm 0.02$ & & $1.469 \pm 0.007$ \\
\hline & 60 & 100 & $300.7 \pm 3.2$ & $2.18 \pm 0.02$ & $1.807^{c}$ & $1.365 \pm 0.005$ \\
\hline & & 50 & $299.6 \pm 2.5$ & $2.34 \pm 0.02$ & & $1.264 \pm 0.004$ \\
\hline & & 200 & $301.4 \pm 2.0$ & $1.90 \pm 0.01$ & & $1.561 \pm 0.006$ \\
\hline & 40 & 100 & $301.7 \pm 2.4$ & $2.07 \pm 0.02$ & $2.065^{c}$ & $1.435 \pm 0.005$ \\
\hline & & 50 & $303.9 \pm 1.5$ & $2.27 \pm 0.01$ & & $1.326 \pm 0.004$ \\
\hline
\end{tabular}

Table.2: Tablet characteristics 


\subsection{Thermal analysis}

The Differential Scanning Calorimetry (DSC) apparatus used for the calorimetric measurements was a Q200 from TA Instruments. For all measurements, aA nitrogen purge of $50 \mathrm{~mL} / \mathrm{min}$ was employed. Aluminium crucibles with perforated caps were used and the heating rate was $10^{\circ} \mathrm{C}$. $\mathrm{min}^{-1}$ from $20^{\circ} \mathrm{C}$ to $270^{\circ} \mathrm{C}$. It was not possible to increase the MCC content in the powder mixture since the endotherm of evaporation hid the transition endotherm from CFII to CFI. Analysis were made in triplicate (i.e., for one batch of caffeine form I, and thus for one composition studied, three tablets were analysed in the same conditions (storage, compression pressure) in order to ensure the reliability of data and the reproducibility of the measurements). DSC takes into account a macroscopic fraction (about $10 \mathrm{mg}$ ) of the tablet and was applied in order to estimate transition degree in tablet parts (core and border) as shown in Figure 2. For the studies of CFI transition degree, a kinetic analysis has been performed for each mixture, at the following specific times: 2, 15, 30, 45, 60, 90 and 180 days after tablets fabrication.

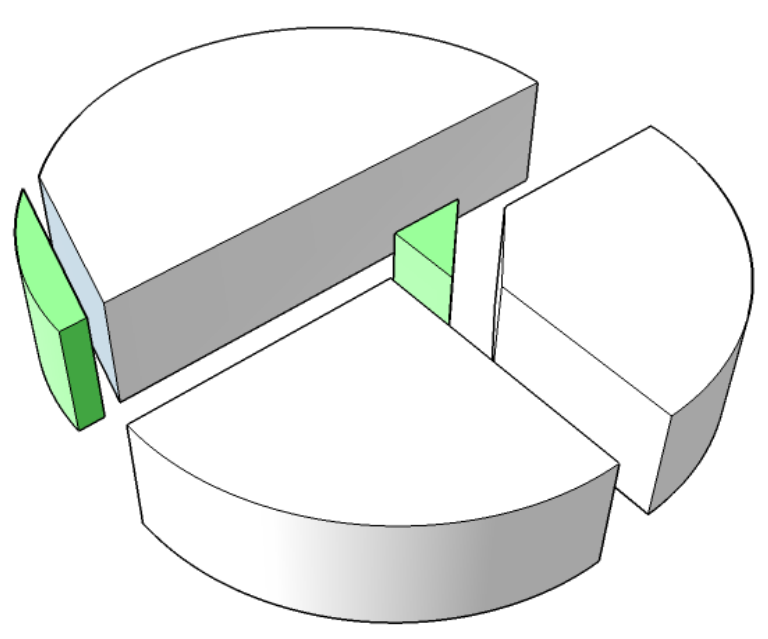

Fig.2. Core and border sample fraction (coloured parts) of tablet for DSC Analysis 


\subsection{Validation of the analytical DSC method to quantify caffeine in tablets}

In this work, the transition temperature $\| \rightarrow$ I of caffeine was measured in triplicate for the commercial anhydrous caffeine Form II. The transition temperature considered $T_{\text {trans }(\|\rightarrow\|)}$ was $140.63 \pm 0.22{ }^{\circ} \mathrm{C}$ and the associated enthalpy of transition $\Delta_{\text {trans }} \mathrm{H}$ was $17.42 \pm 0.76 \mathrm{~J} / \mathrm{g}$. These data are in accordance with the ones find in the literature (collected by Hubert et al., 2011). In order to quantify caffeine in tablets, the three following equations, described by Hubert et al., 2011, are needed. Equation 1 allows correlating between the amount of caffeine Form II in a sample and the enthalpy of transition $\left(\Delta_{\text {trans }} \mathrm{H}\right)$ of pure Form II:

$\%$ of caffeine Form $I I=\frac{\Delta_{\text {trans }^{H}}(I I \rightarrow I) \text { of the sample }}{\Delta_{\text {trans }^{H}}(I I \rightarrow I) \text { of pure form } I I} \times 100$

For tablets made from binary mixtures of CFI and MCC, the dilution impact of the excipient must be taken into account for the calculation of the transition degree of Form I. The total amount of caffeine in the sample is given below by the equation 2 :

$\%$ of anhydrous caffeine $=\frac{\Delta_{\text {fus }} H_{(I)} \text { of the sample }}{\Delta_{\text {fus }} H_{(I)} \text { of pure form I }} \times 100$

The relative amount of caffeine Form II in the tablet corresponds to the transition degree of caffeine Form I into Form II during the compression process. By combining expressions (1) and (2), the transition degree $(\tau)$ after compaction was obtained with equation 3:

$\tau=\frac{\Delta_{\text {trans }} H_{(I I \rightarrow I)} \text { of the sample }}{\Delta_{\text {trans }} H_{(I I \rightarrow I)} \text { of pure form II }} \cdot \frac{\Delta_{\text {fus }} H_{(I)} \text { of pure form } I}{\Delta_{\text {fus }} H_{(I)} \text { of the sample }}$

The experimental validation of this method (shown in Fig.3 and Fig.4) was performed, for each composition studied, in order to confirm the expression (3). According to the tablet formulations, samples of $5 \mathrm{~g}$ were prepared with different ratios of caffeine Form I and Form II. The ratios were 0 $w t \%, 20 w t \%, 40 w t \%, 60 w t \%, 80 w t \%$ and $100 w t \%$ of caffeine Form II compared to the Form I. Three samples were analysed for each ratio. Whatever the diluent used, the maximal relative deviation increased with the caffeine dilution from $3 \%$ to $9 \%$. In the case of $40 \mathrm{wt} \%$ of caffeine with DCPA, this relative deviation goes up to $15 \%$. This explains why a higher dilution of caffeine in the blend containing DCPA as diluent was not studied. 


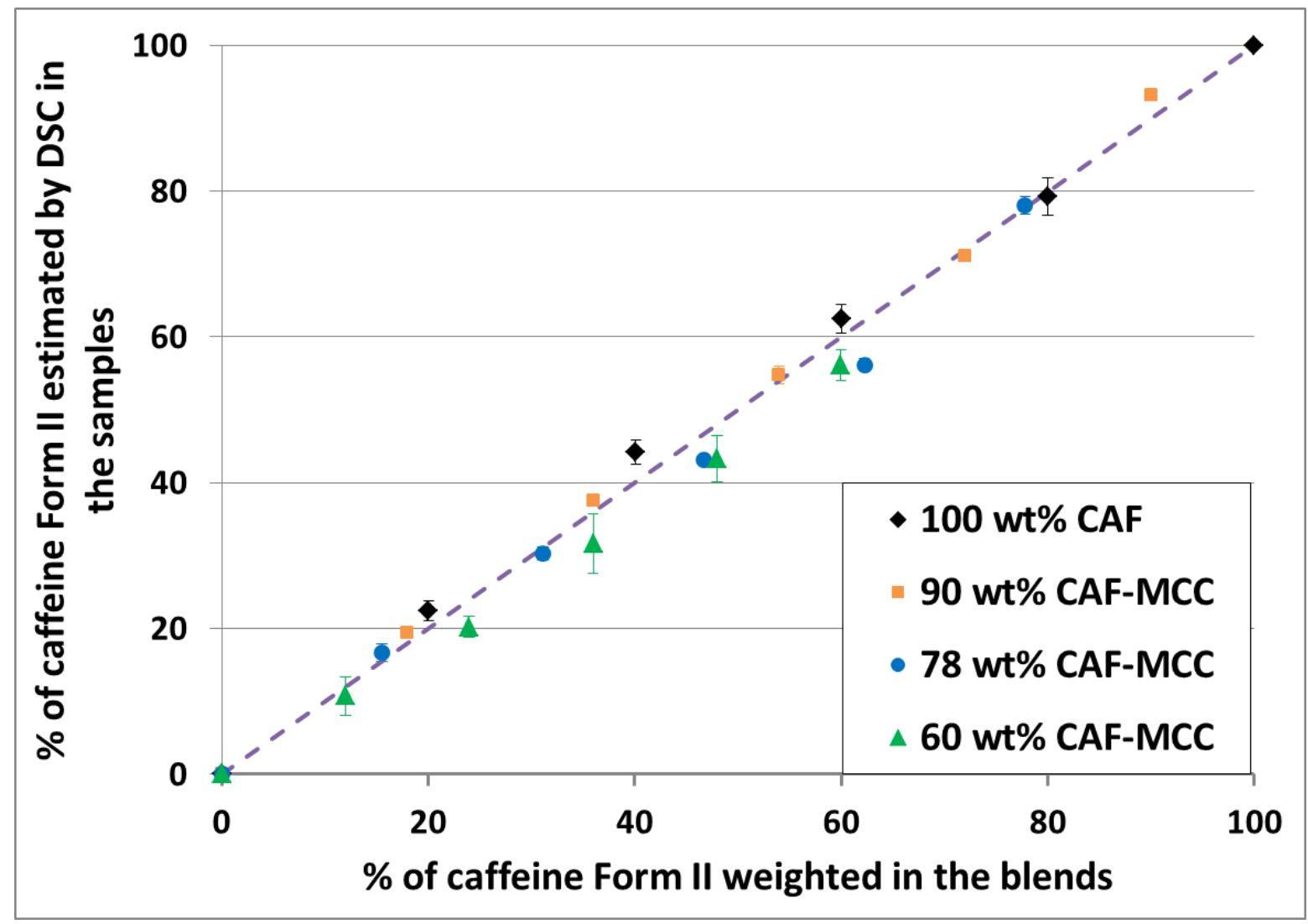

Fig.3. Validation of the quantification method of caffeine Form II in the powder mixture for the pure caffeine and the three blends containing MCC as diluent.

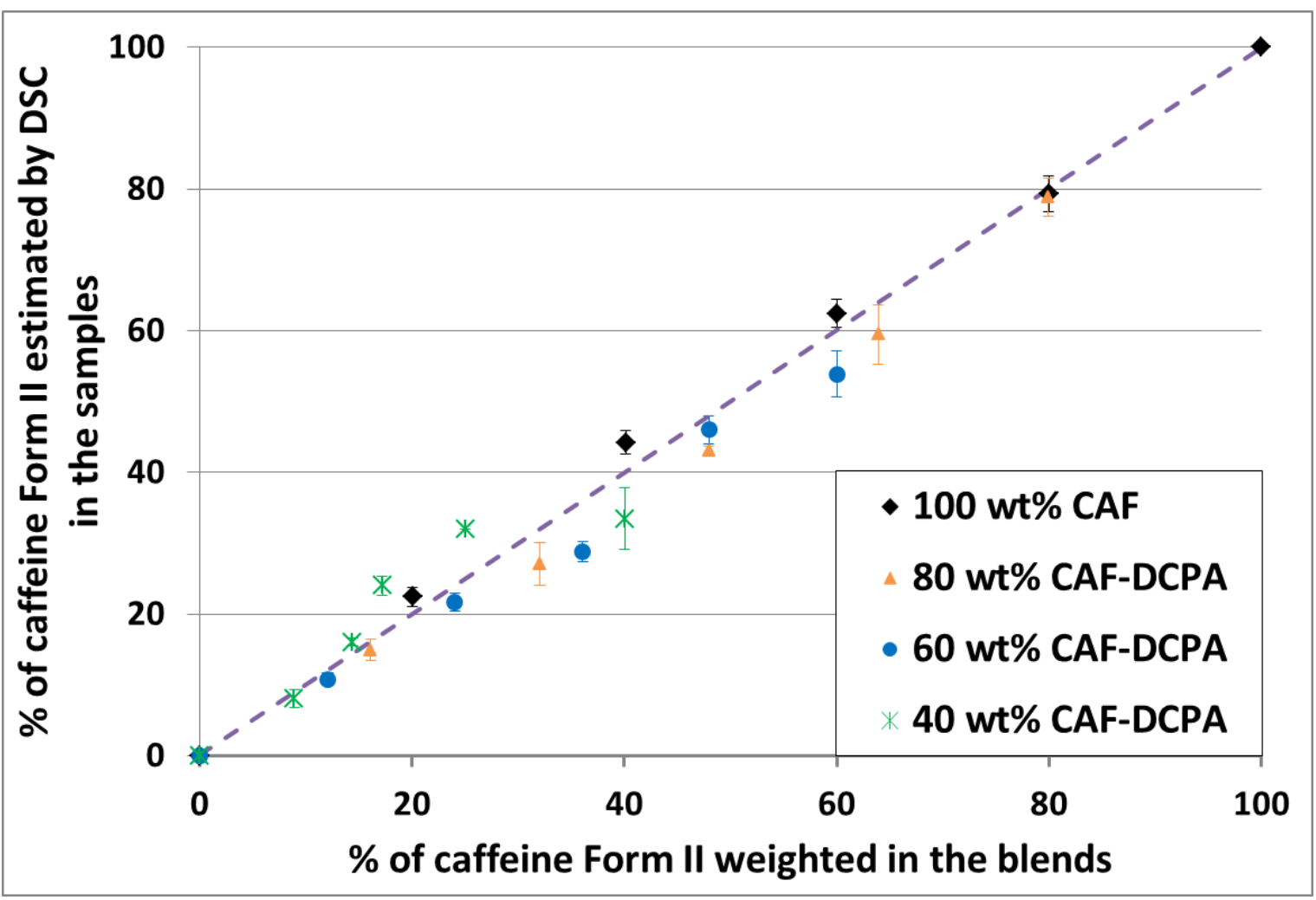

Fig.4. Validation of the quantification method of caffeine Form II in the powder mixture for the pure caffeine and the three blends containing DCPA as diluent. 


\subsection{Statistical analysis}

Statistical analyses were conducted using the R software (The R foundation) with a threshold of $5 \%$ corresponding to the alpha risk. As all data were not normally distributed and variances were not equal, consequently, data could not be normalized, a non-parametric Kruskal-Wallis test was performed. In order to determine significant differences between two parameters, a multiple comparison post hoc test (kruskalmc) was conducted. 


\section{Results}

\subsection{Pure CFI and binary mixtures with MCC as diluent}

\subsubsection{Evolution of the CFI transition degree $(\tau)$ in uncompressed powders}

In uncompressed powders, a kinetic study was conducted during six months in order to observe the evolution over time of the CFI transition degree (see Fig.5). Each curve represents one of the four compositions studied: pure CFI and mixtures CFI/MCC: 90,78 and 60 wt\% of CFI.

Whatever the composition, the transition profile showed a first rapid growth stage over the first 50 days until reaching a plateau from the fiftieth day. For the transition degree values, very small differences appeared between the compositions over the first 50 days, after that, no significant difference was observed. In uncompressed powders, the transition of the caffeine form I into form II seems not be influenced by the dilution of the caffeine with MCC.

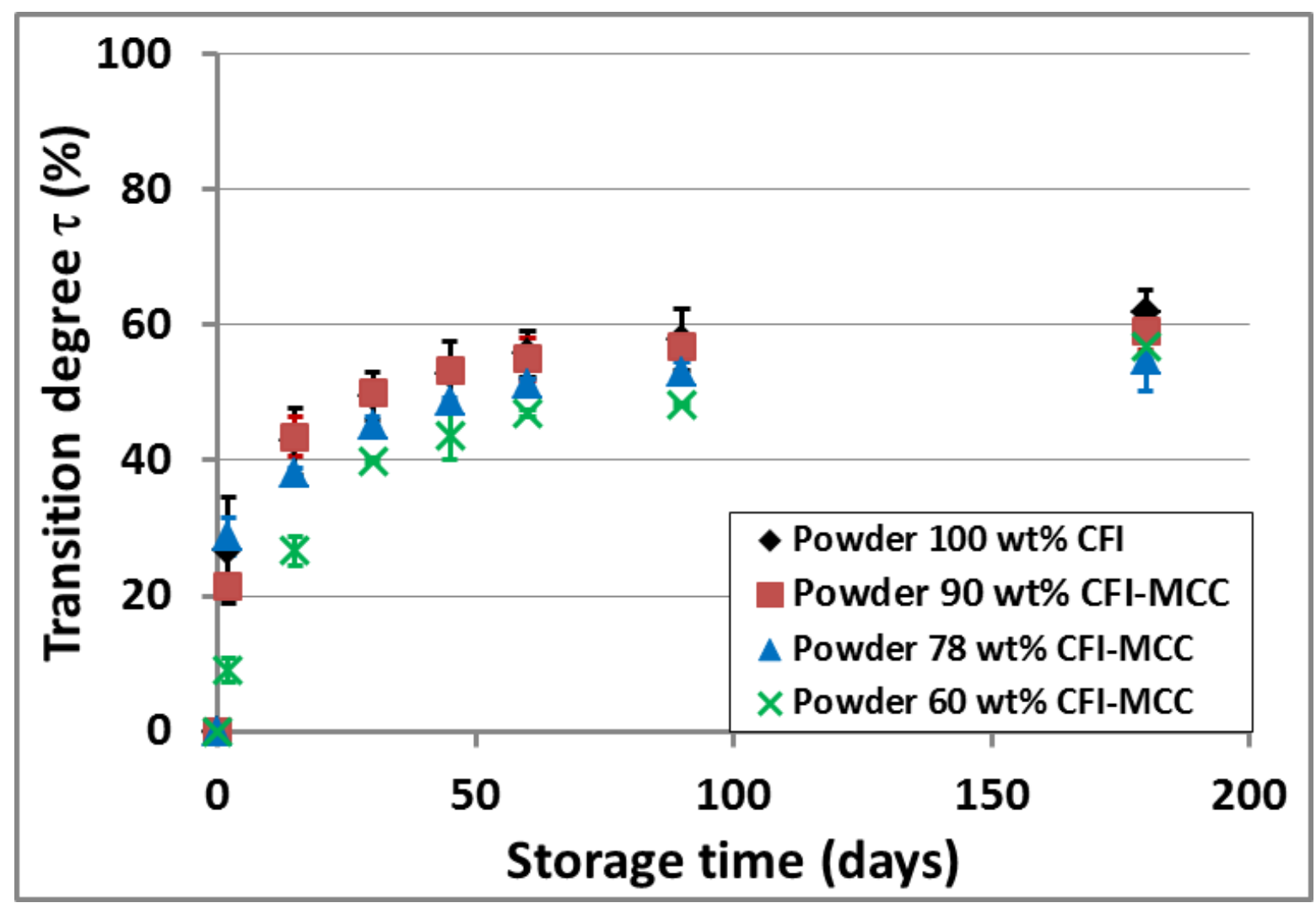

Fig.5: Evolution over time of the CFI transition degree in uncompressed powders for the four binary mixtures (CFI/MCC), $n=3$. 


\subsubsection{Evolution of the CFI transition degree in tablets}

\subsubsection{Is the transition uniform throughout the volume of the tablet?}

The evolution of the CFI transition degree in tablets two days after their fabrication is given in Fig.6. In order to observe the effects of direct compression process on $\tau$, pure caffeine and the three binary mixtures of $\mathrm{CFI} / \mathrm{MCC}$ were analysed. Results observed for tablets were compared to those obtained for uncompressed powders. Analyses were made in triplicate $(n=3)$. Three parameters that may influence $\tau$ were analysed on Fig.6: compression pressure (symbol type), dilution/composition (x-axis) and tablet parts (full or empty symbol corresponding to the borders and the core of tablets, respectively).

Two days after tablet fabrication, the transition of metastable caffeine into its stable form was observed both in tablets and in uncompressed powders. Furthermore, $\tau$ values were higher in tablets than in uncompressed powders. This indicated that CFI transition degree was more important after compression.

For all the compositions, no significant difference on the transition degree was observed between the three compression loads. CFI transition degree was also the same between the core and the border of tablets. The transformation of the caffeine form I into form II could be considered uniform throughout the volume of the tablet. Consequently, for the rest of our study, these results will be combined.

Nonetheless in tablets, significant differences of the transition degree were observed with the compositions. This indicates that unlike uncompressed powders, after compression the transition of the caffeine form I into form II seems to be influenced by the dilution of the caffeine with MCC. 


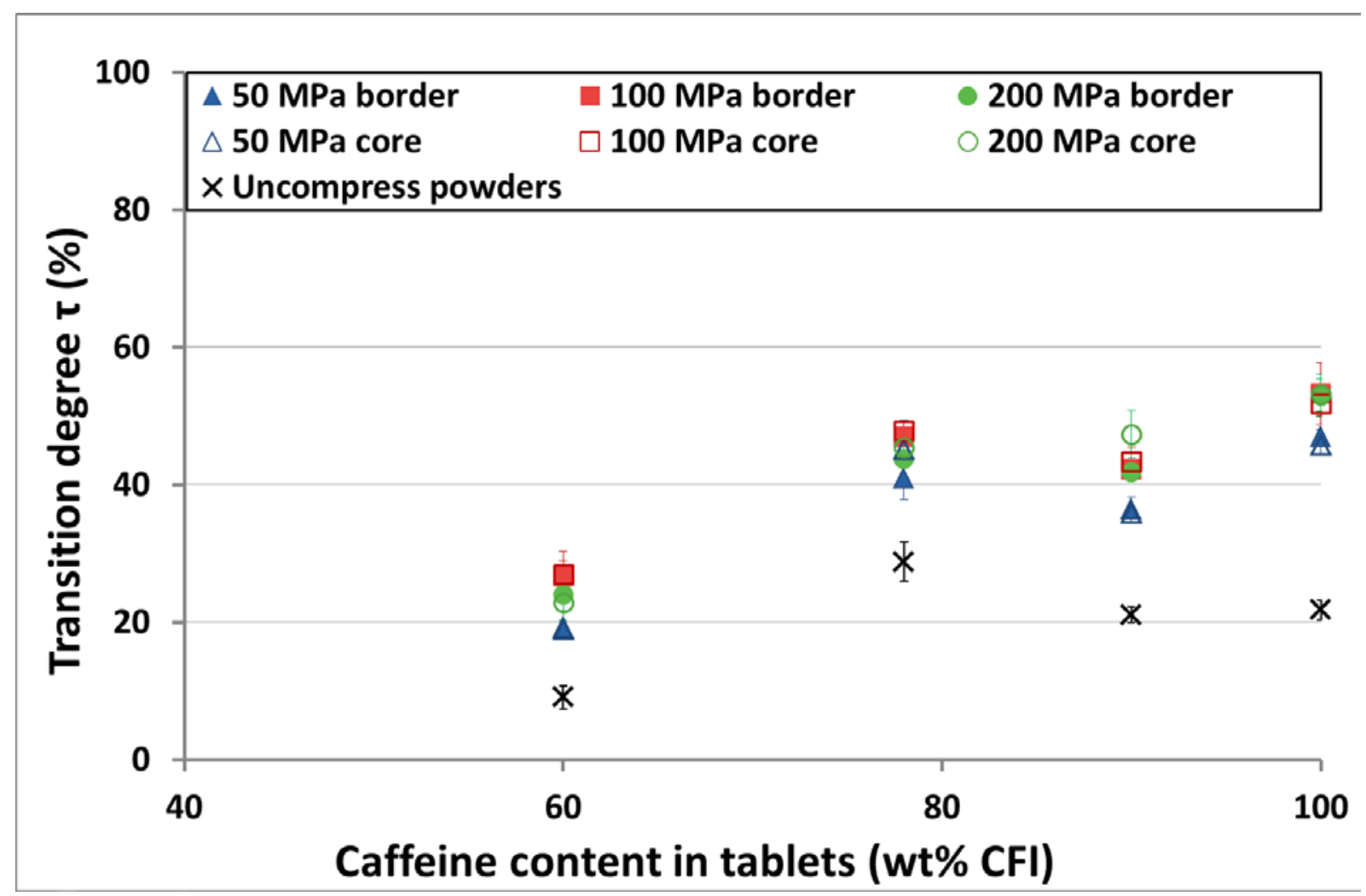

Fig.6: Evolution of the CFI transition degree in tablets two days after their fabrication, $n=3$. 


\subsubsection{Influence of the compression pressure}

Like previously for uncompressed powders, a kinetic study of the CFI transition degree occurring in tablets was also conducted during six months. For each composition, results obtained for tablets were compared to the ones obtained in uncompressed powders. For clarity reasons, Fig. 7 presents the kinetic study of the CFI transition degree for one composition (78 wt\% of CFI). However, the same results were observed for the other compositions.

Uncompressed powder and tablets made at three different compression loads (50, 100 and $200 \mathrm{MPa}$ ) were represented by the black and colour symbols, respectively. In tablets, the $\tau$ profile was similar to the one of uncompressed powder: a first rapid growth stage over the first 50 days until reaching a plateau. All along the kinetic study of the CFI transition degree for pure caffeine and binary mixtures of $\mathrm{CFI} / \mathrm{MCC}$, a constant gap of around $20 \%$ was observed between uncompressed powders and the tablets. The plateau value was more important in tablets than in uncompressed powders. Whatever the composition, no significant difference was observed between the three compression loads. These results mean that the compression pressure doesn't alter the transition of the caffeine form I into form II after compression, but the content of form II was initially more important in tablets than in uncompressed powder.

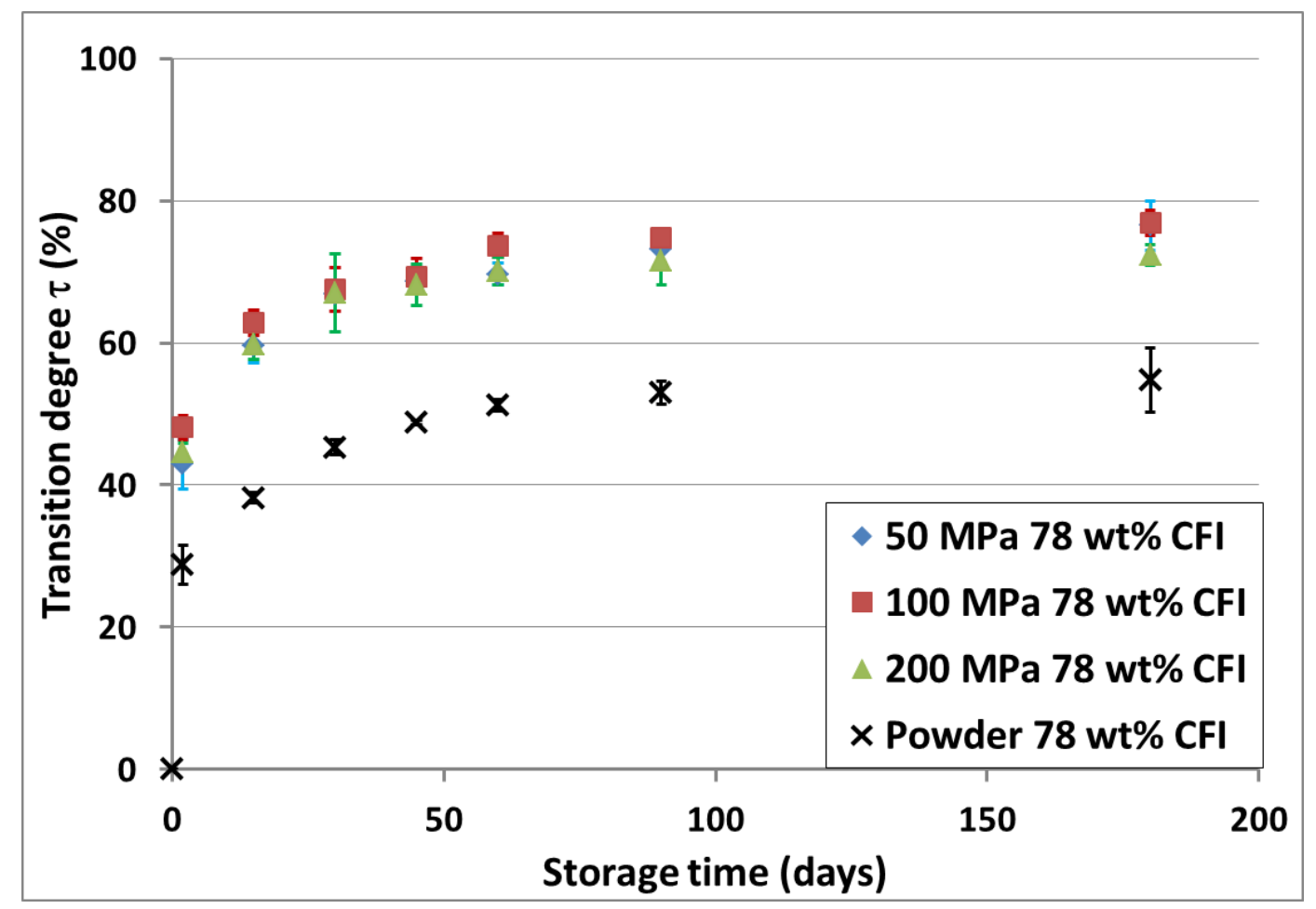

Fig.7: Evolution over time of the CFI transition degree for the composition 78 wt\% of CFI. (powders: $n=3$; tablets: $n=6$ ) 


\subsubsection{Influence of the dilution}

In order to observe the dilution impact on $\tau$, Fig. 8 presents the evolution over time of the CFI transition degree in tablets for pure caffeine and the three binary mixtures of CFI/MCC. As seen before, compression pressure had not an influence on $\tau$, consequently results obtained for tablets made at different compression pressures were regrouped. This means that each dot on figure 8 corresponds to the mean value of eighteen DSC analyses made on tablets. Significant differences between the compositions were observed over time for the $\tau$ values. These results indicate that in tablets, the dilution of caffeine with MCC had an impact on the CFI transition degree: $\tau$ increased with the caffeine content in the blend. These results match up well with the ones obtained two days after tablet fabrication.

Furthermore, the plateau value of the transition degree increased with caffeine content in the blend. In addition, the higher caffeine content in the blend, the faster the plateau value was reached.

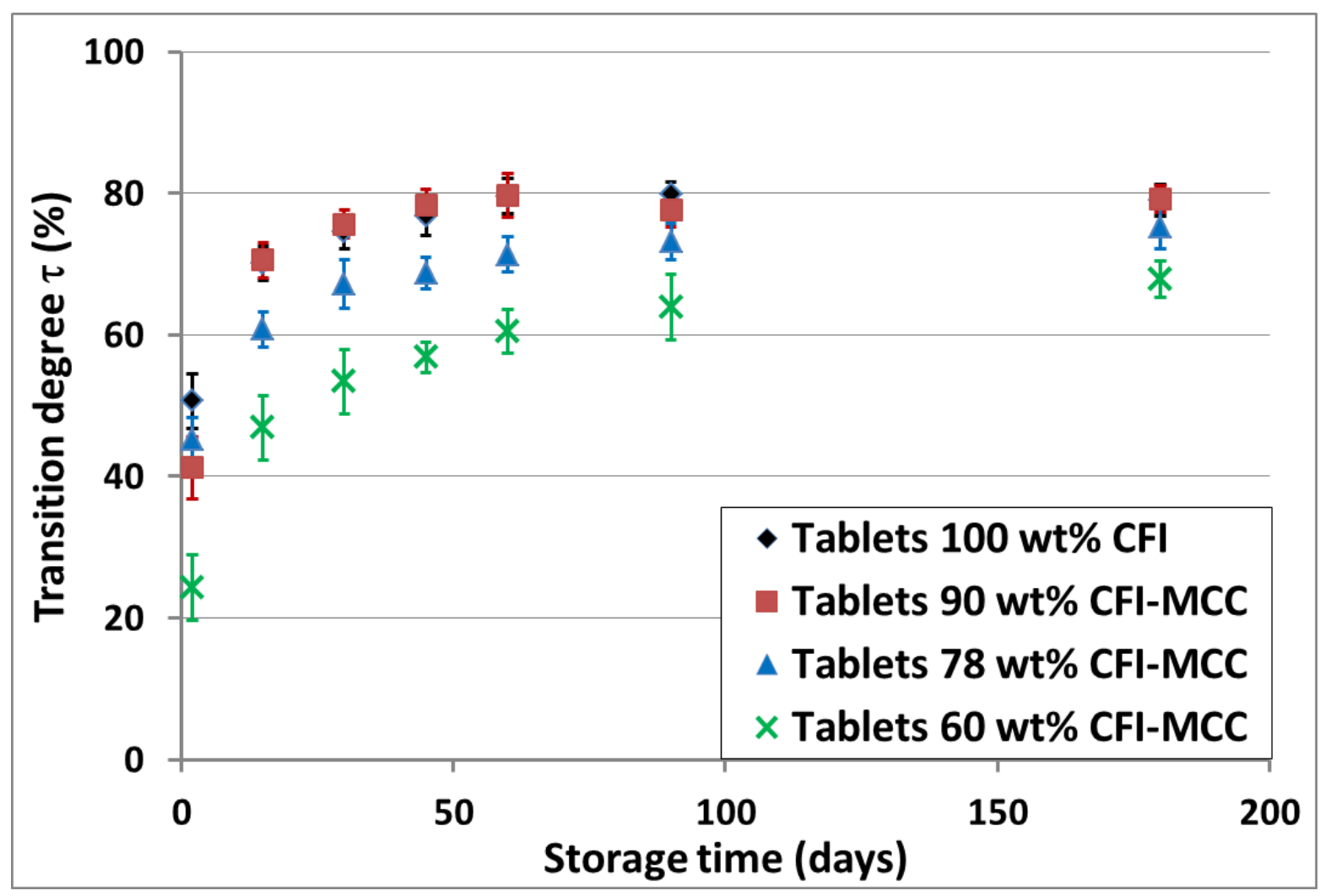

Fig.8: Evolution over time of the CFI transition degree in tablets (mean value of the three compression loads) for the four binary mixtures of CFI/MCC ( $n=18)$.

The plateau values for $\tau$ in tablets and in uncompressed powders are given in Table 3. Whatever the composition, the plateau value was higher in tablets than in uncompressed powders. Moreover, the plateau was more quickly reached for tablets than for uncompressed powders. 


\begin{tabular}{|c|c|c|c|c|}
\hline \multirow[b]{2}{*}{$w t \%$ CFI } & \multicolumn{2}{|c|}{$\begin{array}{c}\text { Uncompressed } \\
\text { powders }\end{array}$} & \multicolumn{2}{|c|}{ Tablets } \\
\hline & $\tau(\%)$ & $\begin{array}{c}\mathrm{Tp} \\
\text { (days) }\end{array}$ & $\tau(\%)$ & $\begin{array}{c}\text { Tp } \\
\text { (days) }\end{array}$ \\
\hline 100 & 62 & 90 & 80 & 60 \\
\hline 90 & 57 & 90 & 80 & 60 \\
\hline 78 & 55 & 90 & 75 & 90 \\
\hline 60 & 55 & 110 & 70 & 90 \\
\hline
\end{tabular}

Table.3: Transition degree $\tau$ at long storage (plateau value) in the cases of uncompressed powder and tablet for several caffeine content blends. Tp: Time plateau. 


\subsection{Binary mixtures with DCPA as diluent}

As indicate in "Tablet preparation" (section 2.2), the storage of uncompressed powders and tablets was made at room temperature and during one year the temperature varies in a range from 18 to $30^{\circ} \mathrm{C}$. Unfortunately, the study of the CFI transition degree of pure CFI, CFI/MCC and CFI/DCPA were not carried out at the same time. Consequently, for tablets it is not possible to compare the pure caffeine with the binary mixtures of CFI/DCPA, neither compare CFI/MCC with CFI/DCPA. Nevertheless, it's still interesting to observe the evolution of CFI transition degree for mixtures containing DCPA as diluent.

\subsubsection{Evolution of the CFI transition degree $(\tau)$ in uncompressed powders}

As well as MCC, a kinetic study was performed during six months in order to observe the evolution over time of the CFI transition degree for binary mixtures composed of CFI and DCPA. In uncompressed powders, evolution over time of the transition of caffeine form I into form II is given in Fig.9. Analyses were made in triplicate. All along the kinetic study, no significant difference was observed whatever the compositions. These profiles are similar with the ones obtained for uncompressed binary mixture of $\mathrm{CFI} / \mathrm{MCC}$.

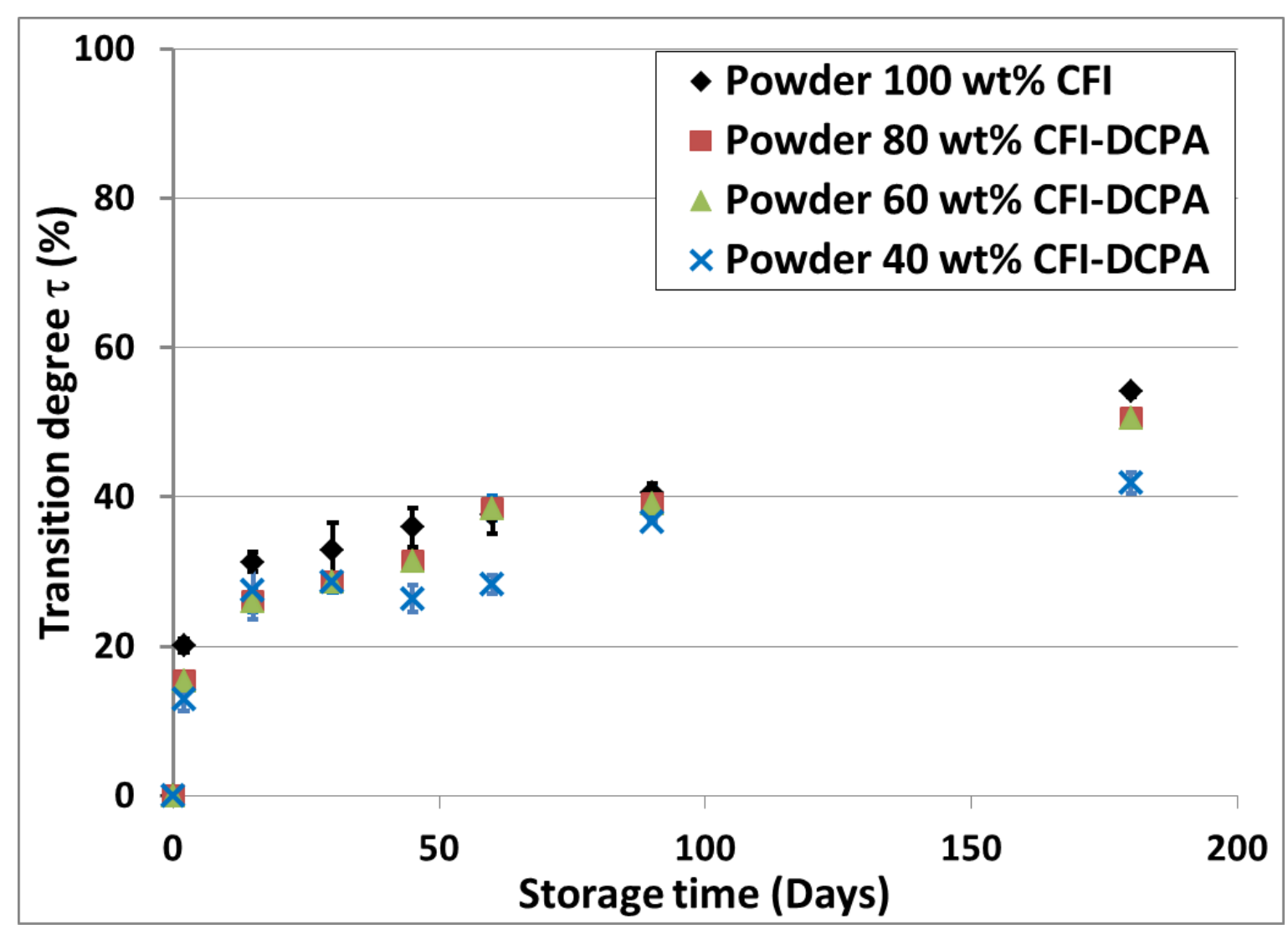

Fig.9: Evolution over time of the CFI transition degree in uncompressed powders for the four binary mixtures (CFI/DCPA), $n=3$. 


\subsubsection{Evolution of the CFI transition degree in tablets}

\subsubsection{Is the transition uniform throughout the volume of the tablet?}

For this study three compositions were analyses: 80,60 and 40 wt\% of CFI qs. DCPA. The evolution of the CFI transition degree in tablets two days after their fabrication is given in Fig.10. In this figure, three parameters that can influence $\tau$ could be analysed: compression pressure (symbol type), dilution/composition ( $\mathrm{x}$-axis) and tablet areas (full or empty symbols corresponding to the borders and the core of tablets, respectively).

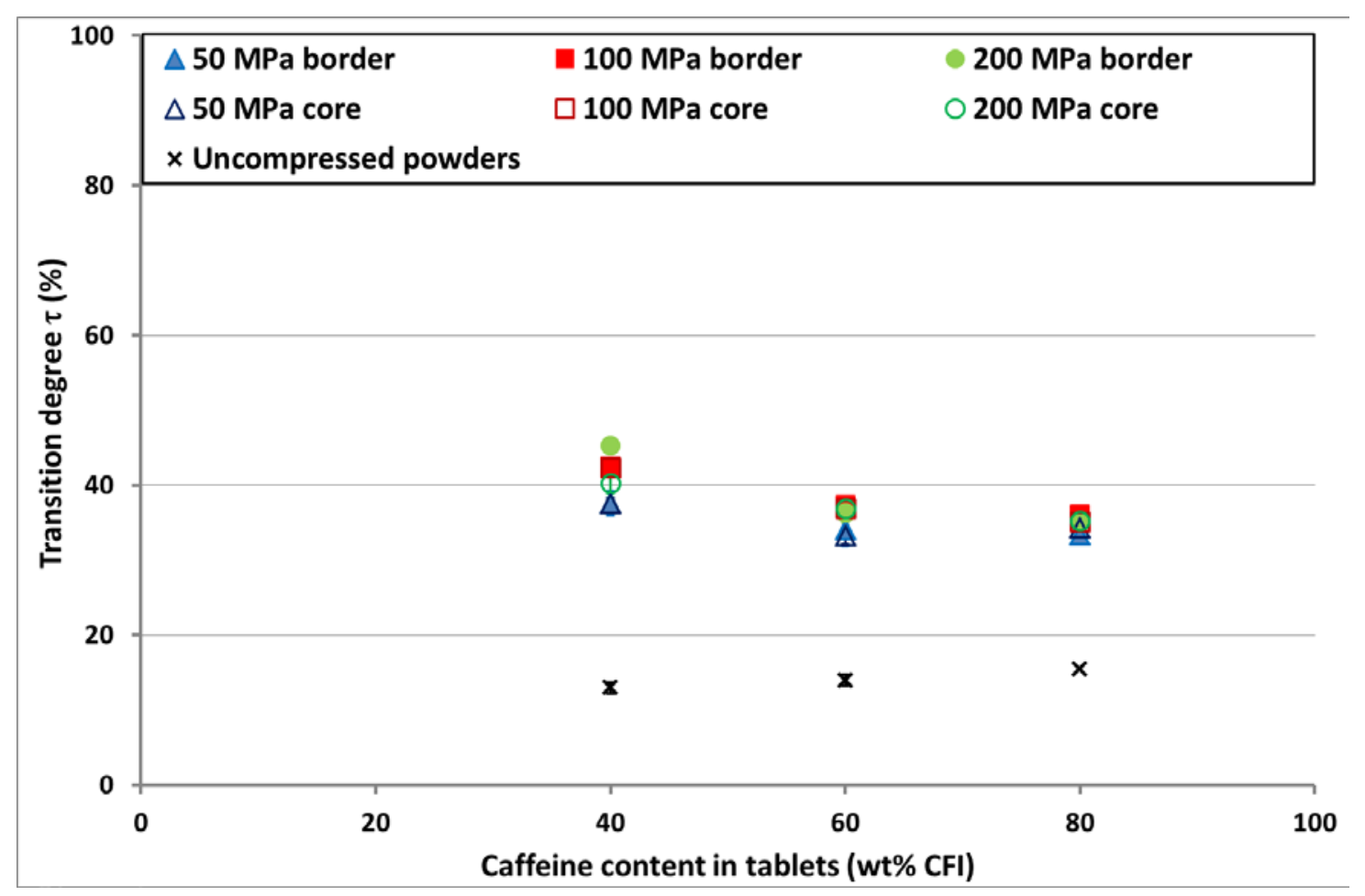

Fig.10: Evolution of the CFI transition degree two days after compression versus the caffeine content in tablets (CFI/DCPA)

Two days after tablets fabrication, the transition of the caffeine form I into form II was observed both in tablets and in uncompressed powders. The $\tau$ values in tablets were more important than those observed in uncompressed powders, these mean that CFI transition degree was more important after compression.

Furthermore, for all the compositions, no significant difference on the transition degree was observed between the three compression loads. The transformation of the caffeine form I into form II uniformly occurred throughout the different parts of the tablet (core and border). Therefore, results obtained for the core and the border of tablets will be combined. Contrary to $\mathrm{CFI} / \mathrm{MCC}$, a small impact of the composition was observed in tablets. 


\subsubsection{Influence of the compression pressure}

For the three binary mixtures containing DCPA as diluent, tablets made from three compression loads $(50,100$ and $200 \mathrm{MPa}$ ) were studied in order to evaluate the influence of this parameter on $\tau$. For each composition, a comparison between uncompressed powder and tablets was made. For clarity purposes, Figure 11 presents only the kinetic study of the CFI transition degree for one composition: $80 \mathrm{wt} \%$ of CFI (the same results were observed for the other ones). Uncompressed powder and tablets made at three different compression loads were represented by the black and colour symbols, respectively.

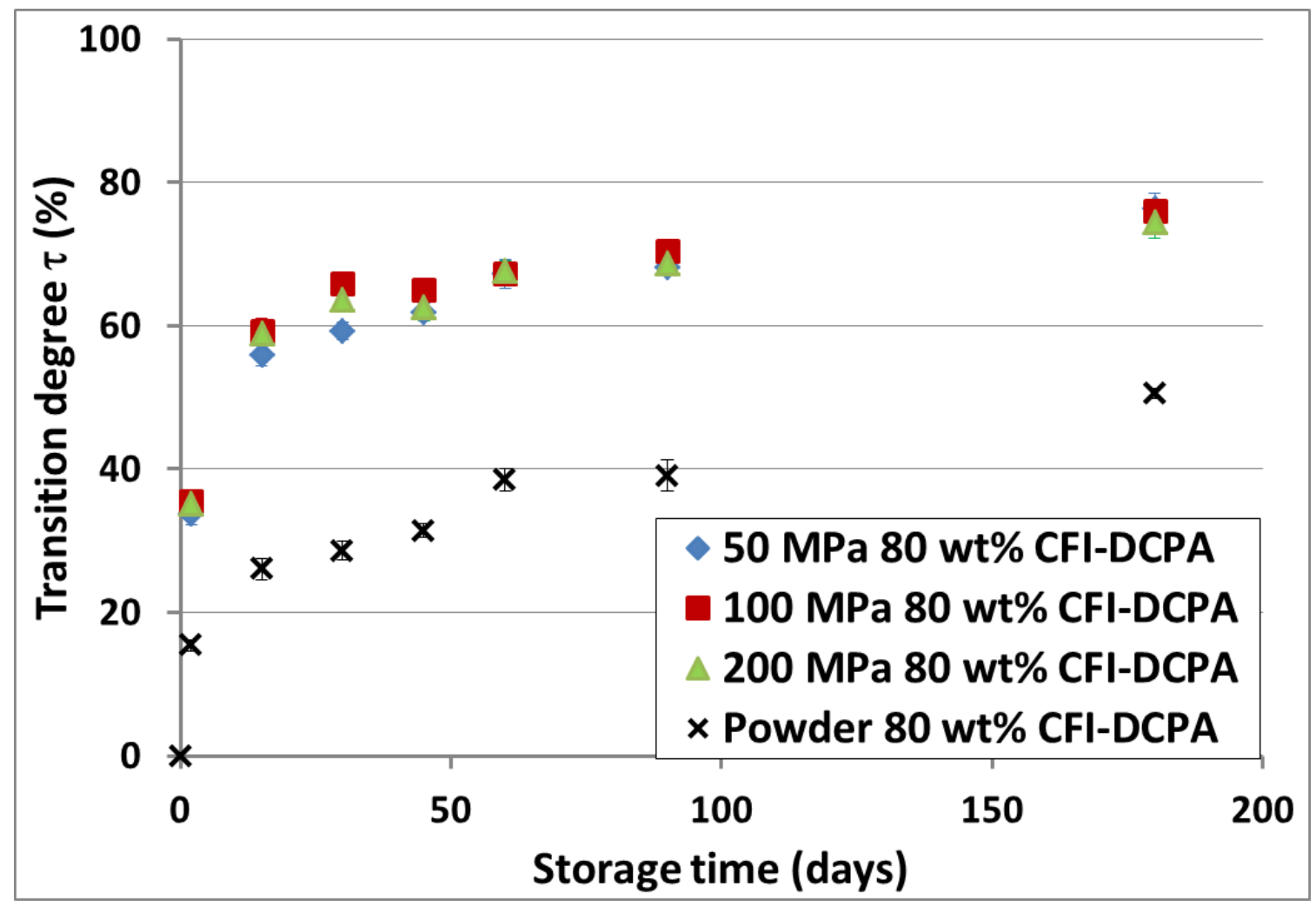

Fig.11: Evolution over time of the CFI transition degree for the composition $78 \mathrm{wt} \%$ of CFI. (powders: $n=3$; tablets: $n=6$ )

The transition degree profile was similar both in uncompressed powder and in tablets. All along the kinetic study of the CFI transition degree for binary mixtures of CFI/DCPA, a constant gap of around $30 \%$ was observed between uncompressed powder and tablets. The transition degree of the caffeine form I into form II continued to increase with time, no threshold level was observed for tau. Different values of the transition degree appeared according to the compression pressure applied over the first 50 days, after that, no significant difference was observed. For binary mixtures of CFI/DCPA, the transition of the caffeine form I into form II did not seem to be influenced by the compression loads. 


\subsubsection{Influence of the dilution}

The time evolution of $\tau$ in tablets for the three compositions (CFI/DCPA) is given in figure 12 . Considering that compression pressure had not an impact on the CFI transition degree, the results obtained for tablets made at different compression loads were regrouped. Little differences on the transition ratio appeared according to the compositions over the first 50 days, after that, no significant difference was observed. The transition degree of the caffeine form I continued to increase with time. In tablets, the dilution of caffeine with DCPA did not influence the CFI transition degree. These results are similar with the ones obtained with the uncompressed powders.

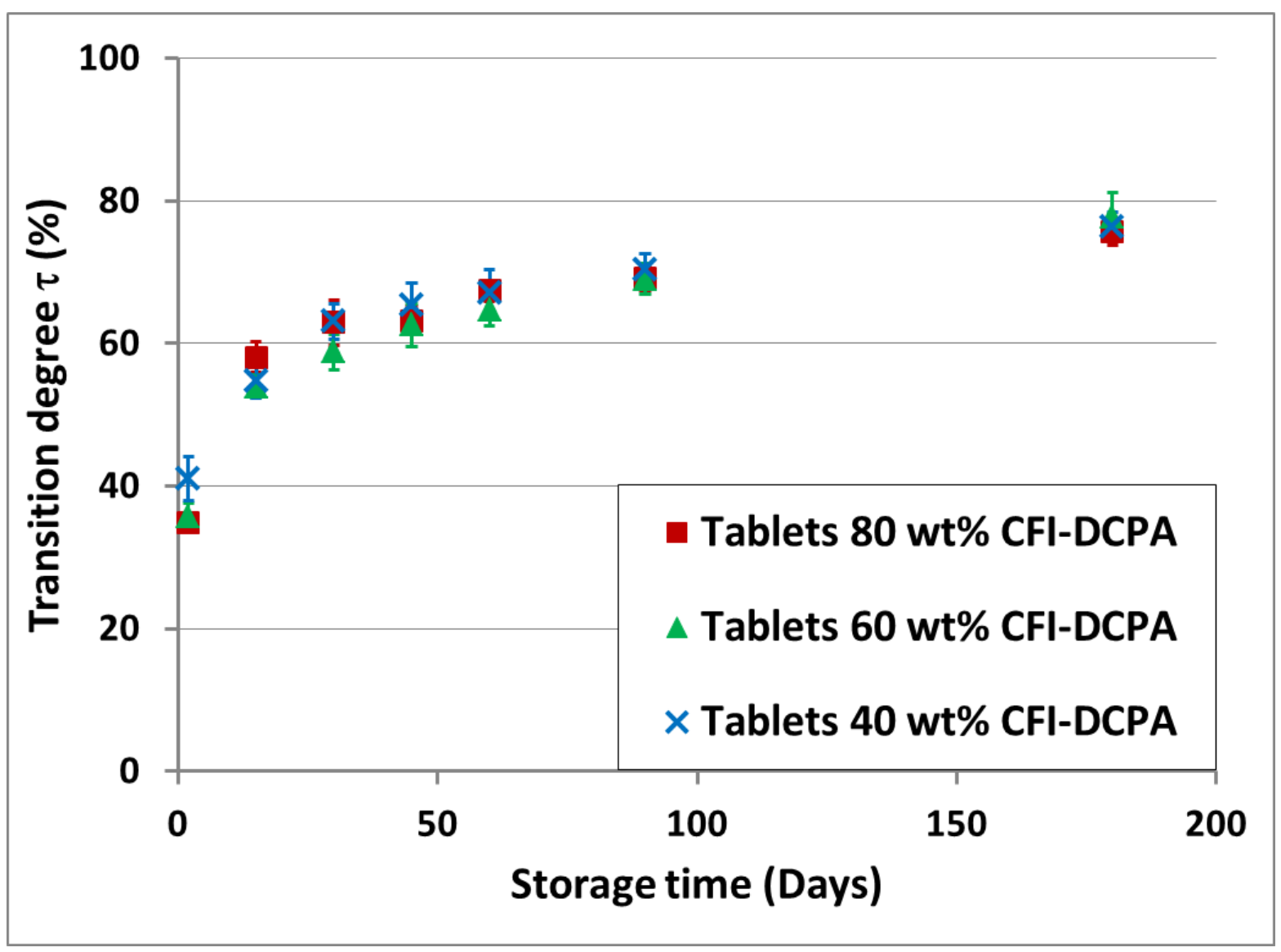

Fig.12: Evolution over time of the CFI transition degree in tablets (mean value of the three compression loads) for the three binary mixtures of CFI/DCPA ( $n=18)$. 


\section{Discussion}

\subsection{Evolution of the CFI transition degree $(\tau)$ in uncompressed powders}

Whatever the diluent used, the transition of pure caffeine form I into form II was rapidly observed in uncompressed powders (two days after the batch production of CFI). These results are consistent with those find in the literature by Mazel et al., (2011) and Hédoux et al. (2011) and confirm that the metastable form I of the caffeine tends spontaneously to move towards its stable form II. At long time storage, the transition kinetic rate is slowed down for two possible reasons: (i) the converted parts in the particle stop their expansion when they are in contact each other (ii) the inner volume fraction of form I available for nucleation of form II decreases.

However, the $\tau$ profiles of mixtures containing MCC shows a first rapid growth stage over the first 50 days until reaching a plateau from the fiftieth day. By contrast, for mixtures containing DCPA, none plateau was reached, CFI transition degree profile presents a first rapid growth stage only over the first 15 days, after that, $\tau$ continue to increase progressively over the time. This difference cannot be explained by the nature of the diluent, but may be due to the batch of caffeine form I and/or to the storage temperature changes (as mentioned previously).

\subsection{Evolution of the CFI transition degree in tablets}

These kinetic studies help to highlight the influence of the diluent on the CFI transition degree. Whatever the diluent used, CFI transition degree was higher in tablets than in uncompressed powders. This means that a part of the transformation was induced by the direct compression process. These results are in accordance with those reported in the literature in compression (Pirttmäki et al., 1993, Mazel et al., 2011) and in hydrostatic pressurizing (Hédoux et al. 2013). Moreover, the compression pressures did not have an impact on $\tau$. In accordance with Hubert et al. (2011), the compression load did not alter the transition degree of the caffeine form I into form II. For CFI, whatever the values of the compression pressure applied in this study, the transition degrees just after compression were similar. One could assume that the compression pressure has just a triggering effect when a sufficient compression pressure is applied in tableting.

It is known that the stress applied during tableting is not uniformly distributed in compact, but the stress and density in compressed powders are localized (Moe and Rippie, 1997). Nonetheless, in agreement with observations made by Hubert et al. (2011), no difference on the transition of the caffeine form I into form II was observed between regions considered (core and border). These observations mean that even if the stress was not uniformly distributed in all parts of the tablet, the transition of $\mathrm{CFI}$ is occurring throughout the tablet volume. This is in accordance with previous results 
which showed that transition degree of the caffeine form I into form II was not affected by the compression level.

The nature of the diluent has an impact on the transition degree occurring during the compression process. Concerning the impact of the API dilution, two situations were observed in function of the diluent used. With MCC, the API dilution had an impact on $\tau$ : CFI transition degree increased with the caffeine content in the blend. Conversely, the effect of the diluent content was not significant for CFI/DCPA mixtures. These differences observed between mixtures containing MCC and those with DCPA could be due to the different behaviour of the diluent under compression. In addition to their different mechanical properties, MCC exhibits a plastic deformation and DCPA a fragmentary behaviour under compression (Ilkka and Paronen, 1993). Indeed, diluents are well known to be able to affect the solid-state transition kinetics of APIs during various unit operations (Alles $\varnothing$ et al., 2009). Schmidt et al. $(2003,2004)$ have studied the potential of some diluents for minimizing polymorphic or pseudopolymorphic transitions of API, which are induced by the tableting process. They have indicated that some diluent could have the ability to partially prevent the transformation of the drug. This difference can be attributed to the different behaviour of the diluent under compression.

The $\tau$ profile in tablet is similar than in uncompressed powder: a first rapid growth step followed by a plateau or a small increasing rate. A constant gap between the two profiles was observed for both diluent. The values of these gaps were not dependent on the caffeine content in mixtures, but differ according to the diluent: a 20\% gap for MCC mixtures and 30\% gap for DCPA mixtures. It means that the transition mechanism is the same, the only difference is due to the higher initial transition value in tablet due to the initial compression load. However, the plateau value was more quickly reached in tablets than with uncompressed powders. Consequently the compression has not only triggered the transition, but the transition mechanism after compression is afterwards more intense.

\subsection{Analysis of the transformation kinetic rate and mechanism of the caffeine form I into form II}

The solid-state transformations are usually controlled by the nucleation and growth processes of the new phase, which is described with a first-order transition kinetic rate. The Johnson-Mehl Avrami (JMA) approach is widely used in studies dedicated to transformation kinetics of powders at solid state (Duan et $a l ., 2015$, Jiang et $a l .$, 2014). The JMA equation is expressed as follows:

$X(t)=1-e^{\left[-\left(\frac{t}{\tau_{A}}\right)^{n_{A}}\right]}$

Where $X$ is the volume fraction of the transformed phase (caffeine form II in this study), $\tau_{A}$ is the overall rate constant that generally depends on the germination rate and its type, as well as growth rate, $n_{A}$ is 
usually known as Avrami's exponent which is characteristic of the growth mode and t represents time. An initial induction time is a general feature of a first order transition, and this induction time increases with the value of $n$ ( $n$ from 1 to 4). Consequently the transition profile is sigmoidal. This sigmoidal Avrami law becomes questionable when the transformation occurs in constrained geometry (Delcourt et al., 1991) like the profile measured in this study. The particle volume could be infinitely subdivided into crystallites so small enough that they are immediately converted once nucleated. The transformed fraction $X(t)$ coincides with the nucleation fraction (Decroix et $a l_{.}, 2008$ ). When the transformation proceeds only by nucleation, without growth process, a stretched exponential law is then used:

$X(t)=1-e^{\left[-\left(\frac{t}{\tau_{N}}\right)^{n}\right]}$

Where $\tau_{N}$, the characteristic kinetic time, is controlled by nucleation only and becomes highly dependent on the cell size. The exponent $n$ is then equal or lower than 1 ( $n=1$ indicate that the crystallites exhibit the same size) By contrast, when crystallites are distributed in size, $\mathrm{n}$ is lower than 1 , meaning that nuclei will appear in the largest ones and were converted first, and therefore, the smallest ones are transformed later (or hardly ever) since the nucleation probability is infinitesimal. Modelling the transition kinetic rate of uncompressed caffeine form I into form II followed at different temperature between 45 to $90^{\circ} \mathrm{C}$ with several techniques like X-Ray diffraction and microcalorimetry (Letho and Laine, 1998), dielectric relaxation (Decroix et al., 2008; Decroix, 2009), Raman spectroscopy (Hedoux et al., 2011b) has been already published in the literature. The stretched exponential law is in good agreement with the experimental data, the value of $\mathrm{n}$ seems to depend on the technique used. With X-Ray diffraction measurement, the reported values of $\mathrm{n}$ are $0.24,0.33$ and 0.37 at $45^{\circ} \mathrm{C}, 60^{\circ} \mathrm{C}$ and $80^{\circ} \mathrm{C}$, respectively. With microcalorimetry, $\mathrm{n}$ varies between 0.37 and 0.47 and with the dielectric relaxation technique $\mathrm{n}$ is about 0.5 .

For this study on uncompressed powders and tablets, the values of $n$ and $\tau_{N}$ were determined according to the expression (5). Results are presented in Table 4. The calculated profiles are shown in Fig. 13 and compared with the experimental points. The mean relative difference between the experimental and the calculated volume fractions is $6 \%$ and $3 \%$ for uncompressed powders and tablets, respectively. This indicates that the transition kinetic rate measured in this study could be represented correctly with this stretched exponential law. The values of $\mathrm{n}$ are in a close range from 0.22 to 0.31 with DCPA as the diluent, and more scattered from 0.19 up to 0.50 with the MCC mixture. These values are in accordance with the ones previously reported in the literature. The presence of the diluent has not a decisive impact on the transformation mechanism, and the exponent value lower than 1 confirms the presence of a distribution of small crystallites, probably a majority of them exhibiting a lower size dimension than the natural length scale (Decroix et al. 2008). 
A comparison of the values of $\mathrm{n}$ and $\tau_{\mathrm{N}}$ obtained between tablets and uncompressed powders bring two indications. First, the values of $\mathrm{n}$ are close. Considering the assumptions of this model, the compression load during tableting had neither reduced the size of the crystallites nor their size distribution. This means that for both situations, the transition mechanism is similar, i.e controlled by the nucleation rate, until a plateau value for which the nucleation frequency is negligible. Secondly, the value of $\tau_{N}$ is several times lower for tablets than for uncompressed powders. The reduction of $\tau_{N}$ is the result of the triggering of the transition during the tableting. At least these considerations are the same whatever the diluent and the caffeine content.

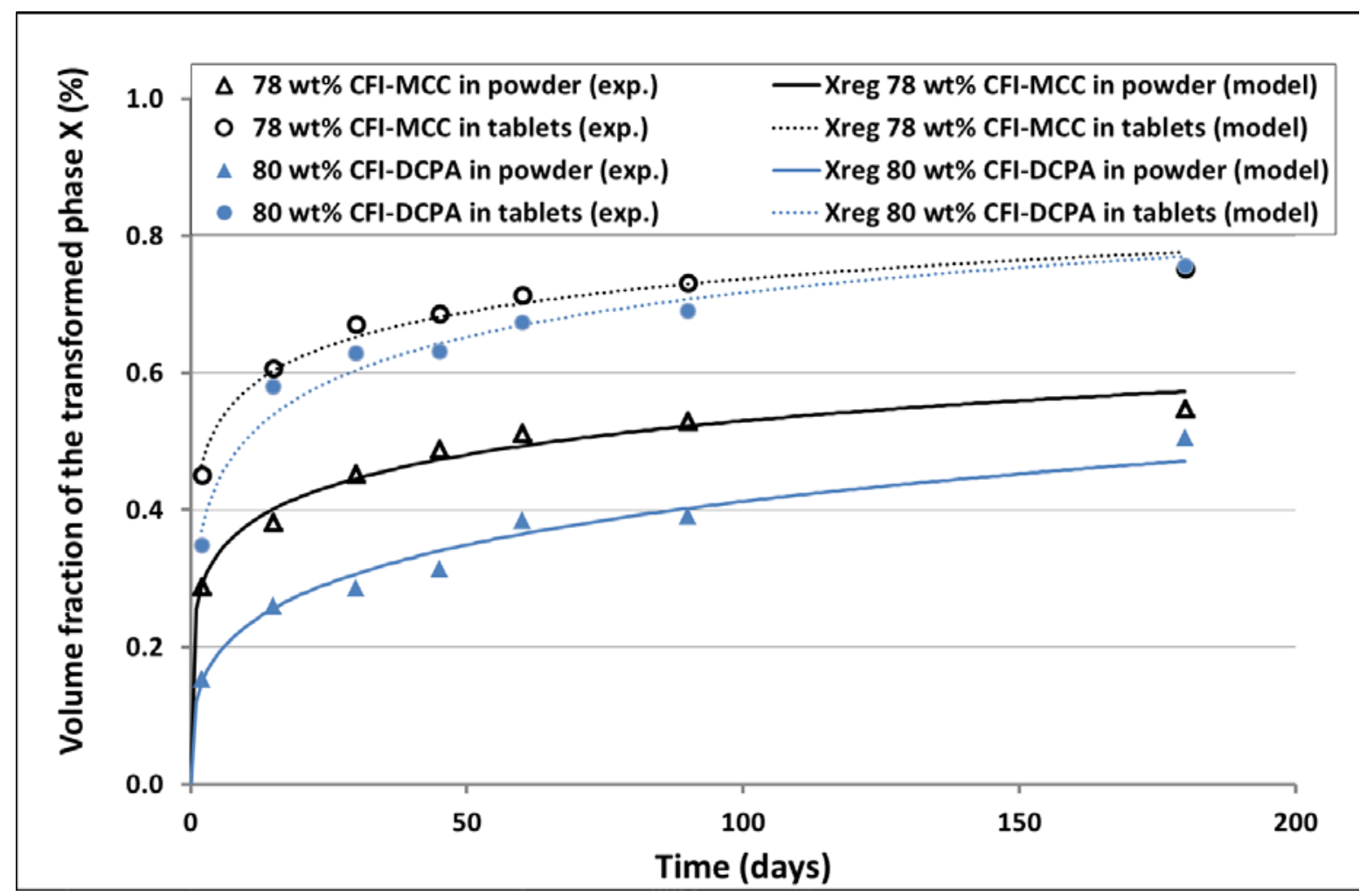

Fig.13: Evolution over time of the volume fraction of the transformed phase. Comparison between experimental data and calculated values obtained from the kinetic laws (5) for uncompressed powder and tablets, respectively.

\begin{tabular}{|c|c|c|c|c|c|}
\hline \multirow{2}{*}{ Diluent } & \multirow{2}{*}{ wt\% CFI } & \multicolumn{2}{|c|}{ Uncompressed powders } & \multicolumn{2}{|c|}{ Tablets } \\
\hline & & $n$ & $\tau_{\mathrm{N}}$ & $\mathrm{n}$ & $\tau_{N}$ \\
\hline \multirow{4}{*}{ DCPA } & 100 & 0.25 & 934 & - & - \\
\hline & 80 & 0.31 & 776 & 0.26 & 40 \\
\hline & 60 & 0.30 & 1321 & 0.26 & 45 \\
\hline & 40 & 0.28 & 1796 & 0.22 & 36 \\
\hline \multirow{4}{*}{ MCC } & 100 & 0.33 & 114 & 0.19 & 8 \\
\hline & 90 & 0.30 & 147 & 0.25 & 13 \\
\hline & 78 & 0.20 & 398 & 0.19 & 23 \\
\hline & 60 & 0.50 & 174 & 0.32 & 84 \\
\hline
\end{tabular}


Table.4: Values of $\tau_{N}$ and $\mathrm{n}$ calculated with the kinetic laws (5) for uncompressed powder and tablets, respectively. 


\section{Conclusion}

In this work, the polymorphic transitions of the caffeine form I into form II that occur during the direct compression process were studied in order to improve the understanding of the PITs. Three parameters that could impact the phase transition of the caffeine form I were analysed: nature of the diluent, dilution of the API and compression pressures. Results shown that the transition degree of the caffeine form I into form II, was higher in tablets than in uncompressed powders. This means that direct compression process has a triggering effect on the polymorphic transition of the caffeine form I

$\rightarrow$ II. Like for uncompressed powders, the transition of the caffeine form I into form II in tablets continue after compression, but starting at a higher value. Moreover, the CFI transition degree in tablets depends on the formulation parameters (diluents used and API dilution). The dilution impact is only observed for mixtures containing MCC. Nevertheless, the processing parameter (compression load) has not an impact on the CFI transition degree.

This study allowed improving the understanding of the transformation of the metastable form of the caffeine (form I) into its stable form (form II) during the direct compression process. A stretched exponential law of the Johnson-Mehl-Avrami model well describes the kinetics transition of the caffeine form I into form II at room temperature in both uncompressed powders and tablets. The tabletting accelerates the polymorphic transition without modifying its mechanism (controlled by nucleation only). Certainly, the protocols reported here should provide referenced methods for investigating solid phase transformations occurred in other oral solid dosage forms such as threedimensional printing tablets (Yu et al., 2009) and electrospun medicated nanofibers (Yu et al., 2015; 2016).

\section{Acknowledgements}

The support of the Ministère de l'Enseignement Supérieur et de la Recherche is gratefully acknowledged. We would like to thank Medelpharm especially T. Ménard, G. Tardy and B. Villa as well as the technician G. Conod-Nardi for her technical support. The authors are also grateful to Pr. Alain Hédoux for stimulating discussions. 


\section{References}

Allesoø, M., Tian, F., Cornett, C., Rantanen, J., 2009. Towards effective Solid Form Screening. J. Pharm. Sci...99, 3711-3718.

Armstrong, N.A., 2002. Tablet manufacture. In: Swarbrick J, ed. Encyclopedia of pharmaceutical technology, vol. 3. $3^{\text {rd }}$ ed. New York: Informa Healthcare Inc., 2723.

Bauer, J., Spanton, S., Henry, R., Quick, J., Dziki, W., Porter, W., Morris, J.- 2001. Ritonavir: an extraordinary example of conformational polymorphism. Pharmaceutical Res. 18, 859-866.

Brittain, H.G., 2002. Effects of mechanical processing on phase composition. J. Pharm. Sci. 91, 15731580.

Boldyreva, E.V., Dmitriev, V., Hancock, B.C., 2006. Effect of pressure up to $5.5 \mathrm{GPa}$ on dry powder samples of chlorpropamide form-A. Int. J. Pharm. 327, 51-57.

Chan, H.K., Doelker, E., 1985, Polymorphic transformation of some drugs under compression, Drug Development and Industrial Pharmacy= 11, 315-332.

Decroix, A.A., 2009. Stabilité physique et désordre orientationnel dans un cristal à usage thérapeutique: la caféine. Ph.D. Thesis. University of Lille 1, France.

Decroix, A.A., Carpentire, L., Descamps, M., 2008. Time-resolved dielectric investigation of relaxation kinetics in metastable caffeine. Philosophical Magazine. 88, 3925-3930.

Delcourt, O., Descamps,M., Hilhorst,H.J., 1991. Size effect in a nucleation and growth transformation, Ferroelectrics. 124, 109-114.

Derollez, P., Correia, N.T., Danede, F., Capet, F., Affouard, F., Lefebvre, J., Descamps, M., 2005. Ab initio structure determination of the high-temperature phase of anhydrous caffeine by X-ray powder diffraction. Acta Crystallographica Section B. 61, 329-334.

Descamps, M., Willart, J.F., Dudognon, E., Caron, V., 2007. Transformation of pharmaceutical compounds upon milling and comilling: the role of Tg.- J. Pharm. Sci., 96, 1398-1407.

Doelker, E., 2002, Modifications cristallines et transformations polymorphes au cours des opérations galéniques. Annales Pharmaceutiques Française. 60, 161-176.

Duan, C.W., HU, L.X., Sun, Y., Zhou, H.P., Yu, H., 2015. Reaction kinetics for the solid state synthesis of the $\mathrm{AlH3} / \mathrm{MgCl} 2$ nano-composite by mechanical milling. Phys. Chem. Chem. Phys. 17, 22152-22159. 
European Pharmacopoeia, 2014. European Directorate for the Quality of Medicines \& HealthCare (EDQM), eighth ed., Strasbourg, France.

Griesser, U.J., Szelagiewicz, M., Hofmeir, U., Pitt, C., Cianferani, S., 1999. Vapor pressure and heat of sublimation of crystal polymorphs. J. Therm. Anal. Calorim. 57, 45-60.

Hédoux, A., Guinet, Y., Descamps, M., 2011. The contribution of Raman spectroscopy to the analysis of phase transformations in pharmaceutical compounds. Int. J. Pharm. 417, 17-31.

Hédoux, A., Decroix, A.A., Guinet, Y., Paccou, L., Derollez, P., Descamps, M., 2011b. Low- and HighFrequency Raman Investigations on Caffeine: Polymorphism, Disorder and Phase Transformation. J. Phys. Chem. B. 115, 5746-5753.

Hédoux, A., Guinet, Y., Paccou, L., Danède, F., Derollez, P., 2013. Polymorphic transformation of anhydrous caffeine upon grinding and hydrostatic pressuring analyzed by low-frequency raman spectroscopy. J. Pharm. Sci. 102, 162-170.

Hubert, S., Briancon, S., Hédoux, A., Guinet, Y., Paccou, L., Fessi, H., Puel, F., 2011. Process induced transformations during tablet manufacturing: phase transition analysis of caffeine using DSC and low frequency micro-Raman spectroscopy. Int. J. Pharm., 420, 76-83.

Ilkka, J. and Paronen, P., 1993. Prediction of the compression behaviour of powder mixtures by the Heckel equation. Int. J. Pharm., 94, 181-187.

Jiang, Y-H., Liu, F., Wang, J-C., Zhang, Z-H, 2014. Solid-state phase transformation kinetics in the nearequilibrium regime. J. Mater Sci., 50, 662-677.

Lefebvre, C., Guyot-Hermann, A.M., Draguet-Brughmans, M., Bouche, R., Guyot, J.C., 1986. Polymorphic transitions of carbamazepine under grinding and compression. Drug Development and Industrial Pharmacy.- 12, 1913-1927.

Lehto, V.P., Laine, E., 1998. A kinetic study of polymorphic transition of anhydrous caffeine with microcalorimeter. Thermochim. Acta 317, 47-58.

Manduva, R., Kett, V.L., Banks, S.R., Wood, J., Reading, M., 2008, Calorimetric and spatial characterization of polymorphic transitions in caffeine using quasi-isothermal MTDSC and localiezd thermomechanical analysis. J. Pharm. Sci.; 97, 1285-1300. 
Mazel, V., Delplace, C., Busignies, V., Faivre, V., Tchoreloff, P., Yagoubi, N., 2011. Polymorphic transformation of anhydrous caffeine under compression and grinding: a re-evaluation. Drug. Dev. Ind. Pharm., 3:, 832-840.

Moe, D.V., Rippie, E.G., 1997. Non-destructive viscoelastic analysis of anisotropy in compressed tablets. J. Pharm. Sci. 86, 26-32

Morris K.R., Griesser, U.J., Eckhardt, C.J., Stowell, J.G., 2001. Theoritical approaches to physical transformations of active pharmaceutical ingredients during manufacture processes. Adv. Drug Deliv. Rev. 48, 91-114.

Otsuka, M., Ibe, K., Tokudome, Y., Ohshima, H., 2009. Nano- and macro- geometrical structural change of caffeine and theophylline anhydrate tablets during hydration process by using X-ray computed tomography. Colloids and Surfaces B: Biointerfaces,. 73, 351-359.

Petit, S., Coquerel, G., 2004. Transformations physiques de cristaux moléculaires induites par les procédés industriels de fabrication: approche théorique, conséquences et exemples. Cristal 3, conférence sur la cristallisation et la précipitation industrielles, Saint-Etienne.

Pinto, S.S., Diogo, P., 2006. Thermochemical study of two anhydrous polymorphs of caffeine. J. Chem. Thermodyn. 38, 1515-1522.

Pirttimakki, J., Laine, E., Ketolainen, J., Paronen, P., 1993. Effects of grinding and compression on crystal structure of anhydrous caffeine. Int. J. Pharm. 95, 93-99.

Sahoo, P., 2015. Molecular recognition of caffeine in solution and solid state. Bioorganic Chemistry. Rev. 58, 26-47.

Schmidt, A.G., Wartewig, S., Picker, K.M., 2003. Potential of carrageenans to protect drugs from polymorphic transformation. Eur. J. Pharm. Biopharm. 56, 101-110.

Schmidt, A.G., Wartewig, S., Picker, K.M., 2004. Polyethylene oxides: protection potential against polymorphic transitions of drugs?- J. Raman Spectrosc. 35, 360-367.

Ticehurst, M.D., Marziano, I., 2015. Integration of active pharmaceutical ingredient solid form selection and particle engineering into drug product design. Journal of Pharmacy and Pharmacology.; 67, 782802. 
Wu, C.Y., Seville, J.P.K, 2009. A comparative study of compaction properties of binary and bilayer tablets. Powder Technol. 189, 285-294.

Yu, D.G., Branford-White, C., Ma, Z.H., Zhu, L.M., Li, X.Y, Yang, X.L., 2009. Novel drug delivery devices for providing linear release profiles fabricated by 3DP. Int. J. Pharm. 370, 160-166.

Yu, D.G., Li, X.Y., Wang, X., Yang, J.H., Bligh, S.W.A., Williams, G.R., 2015. Nanofibers fabricated using triaxial electrospinning as zero order drug delivery systems. ACS Appl. Mater. Interfaces. 7, 1889118897.

YU, D.G., Yang, C., Jin, M., Williams, G.R., Zou, H., Wang, X., Bligh, S.W.A., 2016. Medicated janus fibers fabricated using a Teflon-coated side-by-side spinneret. Colloids and Surfaces B: Biointerfaces. 138, 110-116.

Zhang, Y., Law, Y., Chakrabarti, S., 2003. Physical properties and compact analysis of commonly used direct compression binders. AAPS Pharm. Sci. Tech., 4, Article 62.

Zhang, G.G.Z., Law, D., Schmitt, E.A., Qiu, Y., 2004. Phase transformation considerations during process development and manufacture of solid oral dosage forms. Adv. Drug Deliv. Rev. 56, 371-390. 